\title{
Counting cells in cerebrospinal fluid collected directly on membrane filters
}

\author{
F. BURECHAILO AND T. A. CUNNINGHAM
}

From the Department of Pathology, University Hospital, Saskatoon, Saskatchewan, Canada

SYNOPSIS Accurate enumeration of cells in the cerebrospinal fluid is not feasible with the current method of counting cells in the Fuchs Rosenthal or Neubauer chamber when the count is near normal since the volume of fluid examined is too small. A sample of adequate volume to permit such accurate assessment may be collected from the lumbar puncture needle into a syringe through a ruled membrane filter in a Swinney cartridge. A study of 291 samples shows that the upper limit of the normal cerebrospinal fluid count is 2000 cells $/ \mathrm{ml}(2 / \mathrm{cmm})$ and not $5000 / \mathrm{ml}(5 / \mathrm{cmm})$ as is currently accepted.

Enumeration of the cells in cerebrospinal fluid is an accepted aid in evaluating nervous disorders. When there is a gross pleocytosis great accuracy in counting is of little clinical importance but when the fluid is clear and the total number of cells less than $10000 /$ $\mathrm{ml}(10 / \mathrm{cmm})$ greater accuracy than that afforded by conventional methods would be helpful. This is particularly urgent in managing the therapy of cases of meningeal leukaemia.

The fundamental difficulty with counting chamber methods is the smallness of the sample size. The Fuchs Rosenthal chamber, though larger than the Neubauer chamber, only provides $0 \cdot 18 \mathrm{cmm}$ sample per large square. Clearly the detection limit of these instruments is only slightly better than the commonly accepted upper limit of normal. The fact that wet chamber methods make confirmatory checking impracticable aggravates the difficulty.

Both of these wet chamber methodological difficulties can be circumvented by the use of a membrane filter in a Swinney cartridge (Millipore Ltd, Ville St Laurent, Quebec, Canada) as a combined counting chamber cytology preparatory instrument. A sample size of approximately $1 \mathrm{ml}$ is used and the results are reported as cells $/ \mathrm{ml}$ in order to distinguish these reports from conventional counts. The expected improvement in accuracy of counts in the normal range can be realized and indeed it would appear that the accepted upper limit of normal is too high.

Membrane filters are already an accepted means of evaluating cerebrospinal fluid cytologically for malignant cells (Kline, 1962; Naib, 1970; Wertlake, Markovits, and Stellar, 1972) and also a means of Received for publication 12 November 1973. recognizing pathogens (Jéquier and Dufresne, 1972). The method described here permits these objectives also to be achieved on a routine basis.

\section{Materials and Methods}

MAKING THE CYTOLOGICAL PREPARATIONS The filters used were Millipore RAWGO1300 in a Swinney cartridge (Millipore XX3001200). This instrument has a stainless steel grid to support its filter membrane during the dispensing of bacteriafree solutions. If the cartridge is assembled with its membrane and supporting grid reversed as in fig 1 , it may be directly interposed between the lumbar puncture needle and a syringe. The syringe serves both to aspirate the fluid and to estimate its volume. The filtrate may be used for chemical analysis but not of course for microbiological study. The cartridge and filter assembly is autoclaved before use. When a sample has been collected the entire unopened cartridge is transferred to a jar of $50 \%$ ethanol for prefixation during transport to the laboratory where the filter is processed by standard cytological methods and becomes a permanent preparation.

\section{COUNTING THE CELLS}

The use of the ruled membrane filter facilitates counting of nucleated cells. A hand tally is also helpful. The total number of cells on the filter may be counted or it may be calculated from the number in a single square.

The volume of filtrate from which the deposited cells were derived may be estimated from the calibrations of the syringe, held in the needle-up 

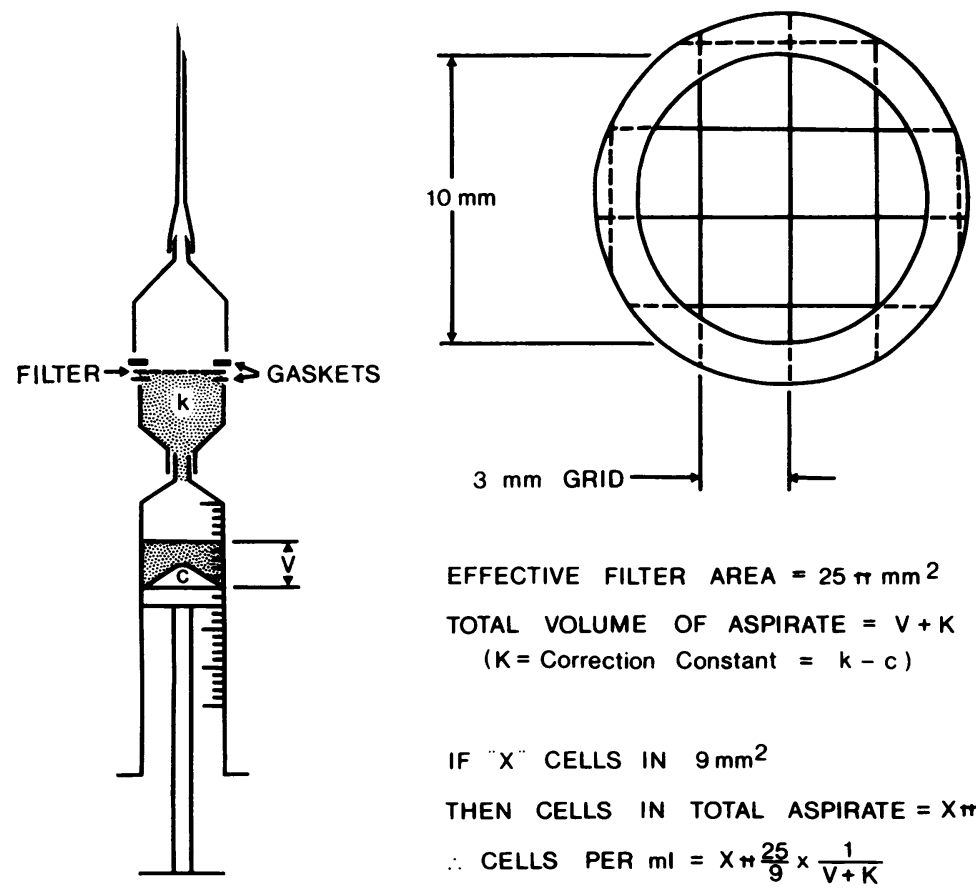

Fig 1 Diagram of filter membrane and cartridge

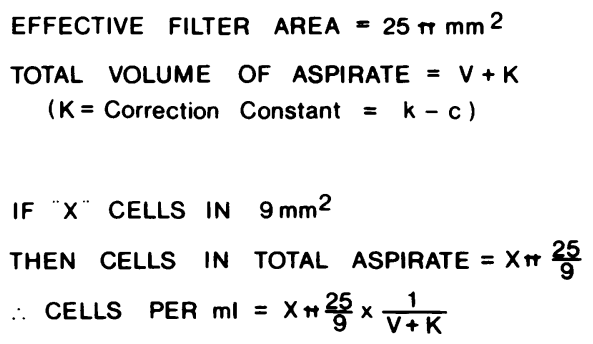

position (fig 1). As this type of disposable syringe has a conical piston a correction (c) must be applied for its displacement, as well as for the dead space in the syringe hub and cartridge on the effluent side of the filter (k). The value of this correction $K=k-c$ was measured by comparing the volume $\mathrm{V}$ estimated from the syringe scale with the weight gain of the syringe cartridge assembly when about $1 \mathrm{ml}$ of distilled water had been aspirated. By removing and drying the distal part of the cartridge and by blotting the water down to the level of the filter only that water which had passed through the filter was included in this measurement. For this syringe type the correction $\mathrm{K}=0.2 \mathrm{ml}$ must be added to the observed volume $\mathrm{V}$ to obtain the volume of fluid contributing the filtered cells.

CALIBRATION WITH KNOWN LEUCOCYTE SUSPENSIONS

A series of dilutions of leucocyte-rich EDTA anticoagulated plasma was prepared and cell counts were performed on a model B Coulter counter (Coulter Electronics, Miami, Florida).

Approximately $1 \mathrm{ml}$ samples of these dilutions were aspirated through cartridges and their actual volume was estimated from the syringe scale as above. The stained filters were counted and the result calculated as above.

\section{Clinical Application}

An autoclaved cartridge-ruled filter assembly was included in each set of lumbar puncture equipment.

Twenty-eight patients without overt disease of the central nervous system having a lumbar puncture for spinal analgesia were sampled initially. These patients were from 40 to 91 years of age (mean $72 \cdot 6$ years).

When the first drop of fluid appeared and showed a clean tap, the cartridge, attached to a $5 \mathrm{ml}$ Tomac syringe, was applied to the needle, and about $1 \mathrm{ml}$ of cerebrospinal fluid aspirated. The nominal volume with the syringe in the cartridge-up position was recorded. The cartridge was transported to the laboratory in $50 \%$ ethanol.

This method has also been applied 402 times to patients with a variety of clinical disorders in whom involvement of the central nervous system was suspected. In all of them Neubauer counts were also done by the technologists in the routine haematology laboratory. The residue of the tube sample was applied to another Millipore filter for comparison.

\section{Results}

A typical set of leucocyte dilutions counted both by the model B Coulter counter and by the cartridge 


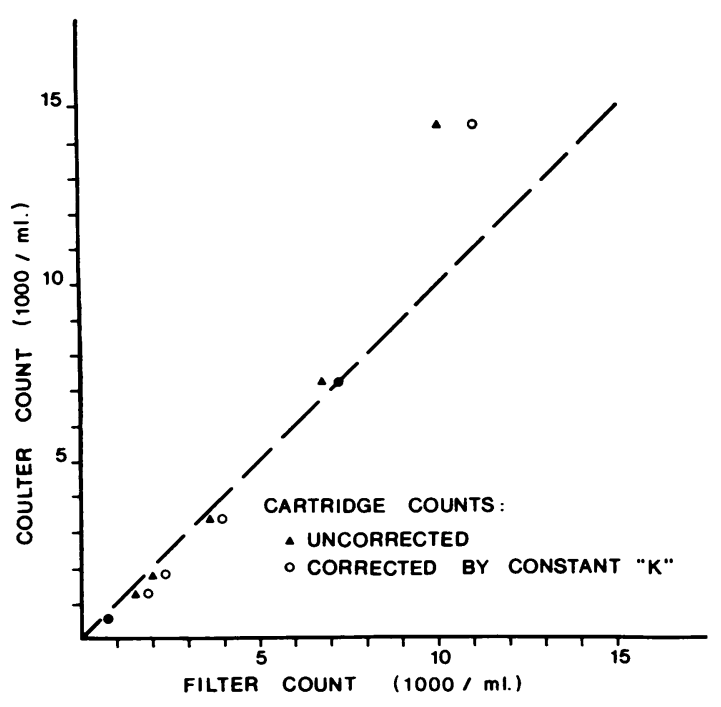

Fig 2 Comparison of cartridge counts of leucocyte suspensions with Coulter counts of the same suspensions

counting chamber is shown in figure 2 . A negative error is apparent for counts above $10000 / \mathrm{ml}$ due to overlapping cells but there is good agreement for counts in the normal range.

SPECIMENS FROM PATIENTS WITHOUT OVERT DISEASE OF THE CENTRAL NERVOUS SYSTEM The cell counts in the samples collected during the spinal analgesia ranged from $230 / \mathrm{ml}$ to $1800 / \mathrm{ml}$ (mean $731.9 / \mathrm{ml}$ ). There were a few atypical cells in the specimen from the patient with $1800 / \mathrm{ml}$ who had metastatic transitional cell carcinoma, but at a subsequent necropsy no metastases in the central nervous system were found. The significance of this is unclear.

SPECIMENS FROM PATIENTS SUSPECTED OF DISEASE OF THE CENTRAL NERVOUS SYSTEM In 130 instances the Neubauer count was greater than $25 / \mathrm{cmm}$ and the number of cells in the cartridge was too high to count. In 263 instances involving 175 patients a countable cartridge was available. These counts are compared with the corresponding Neubauer counts in figure 3.

The values for both methods agreed within \pm $2000 / \mathrm{ml} 135$ times but in the others the differences were greater. The largest bar in fig 3 corresponds to values which were less than $2 / \mathrm{cmm}$ by both methods. There is, however, an excess of entries along the right side, representing samples with much higher Neubauer counts than cartridge counts. These are 16 cases where the cartridge count was less than
$2000 / \mathrm{ml}$ but the Neubauer count was $5 / \mathrm{cmm}$ or more. Review of these showed only one (the case of Parkinsonism referred to below, with a Neubauer count of $7 / \mathrm{cmm}$ ) in which there was other evidence of organic disease of the central nervous system. Some of these samples were slightly contaminated with red cells, and in many of them the routine tube sample was found to be contaminated with glove powder when the filter prepared from the sample residue was examined. The contaminants had presumably been counted as cells by the Technician performing the Neubauer count. The remaining cases do not show a systematic difference between the methods though the correlation is poor. In cases where there were several counts on the same patient, it was the Neubauer counts which showed the greater fluctuations.

All of the patients with a cartridge count of greater than $2000 / \mathrm{ml}$ were judged by other criteria to have significant disease of the central nervous system. There were also eight cases with a cartridge count between $1000 / \mathrm{ml}$ and $2000 / \mathrm{ml}$ in which lesions of the central nervous system were thought to be probable. These included two cases of multiple sclerosis, four cases of Parkinsonism, and two cases of convulsions of which one was associated with a Coxackie B infection. This last case had a $4 / \mathrm{cmm}$ Neubauer count whilst the others were all less than $2 / \mathrm{cmm}$ being zero in four.

Most of those with cartridge counts of less than $1000 / \mathrm{ml}$ were ultimately judged not to have neurological damage but there were of course some patients (11 cases) with organic lesions in whom low counts were found. These were nine cases of Parkinsonism and two cases of unexplained convulsions. One of

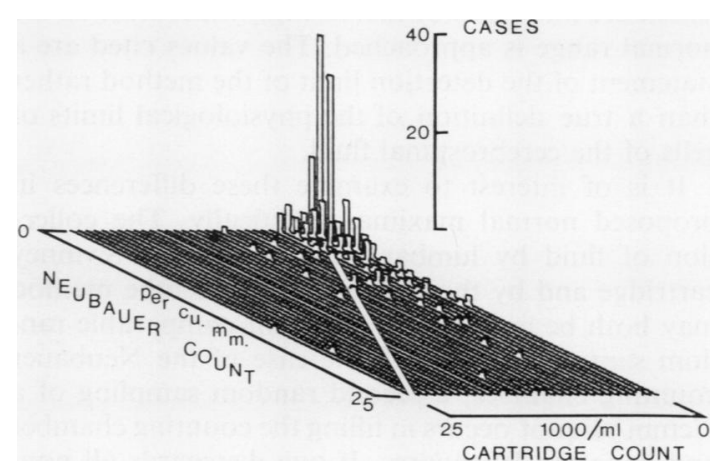

Fig 3 This is a computer-generated frequency histogram to show the distribution of cerebrospinal fluid counts by the Neubauer (cells/cmm) and the Swinney cartridge (cells/ml) in 263 patients clinically suspected of neurological disease in whom both methods yielded results less than $25 / \mathrm{cmm}$ 
the cases of Parkinsonism had a blood-contaminated tap and had a Neubauer count of $7 / \mathrm{cmm}$ which was probably erroneous as judged by the cells seen on the filter of the tube sample residue. One other case of Parkinsonism had a slightly bloodstained tap with a Neubauer count of $2 / \mathrm{cmm}$. The Neubauer count for the others was zero.

\section{Discussion}

Comparison of the present method with the model B Coulter counter using dilutions of leucocyte-rich plasma shows very good agreement in counting cell populations in the normal range. A negative error due to overlapping cells on the filter would be increasingly large at values greater than $10000 / \mathrm{ml}$ but, since such specimens are in any event clearly pathological this is not a clinically significant disadvantage.

None of the 28 patients without overt disease of the central nervous system had a count greater than $2000 / \mathrm{ml}$ and all of the clinically suspect patients who had a cartridge count greater than $2000 / \mathrm{ml}$ proved to have organic disease. From this experience we feel disposed to revise downwards the acceptable upper limit to $2000 / \mathrm{ml}(2 / \mathrm{cmm})$. Specimens between 1000 and $2000 / \mathrm{ml}$ require careful cytological evaluation before being accepted as normal. Specimens with counts as high as $5000 / \mathrm{ml}$ - the usually accepted upper limit-are in fact well into the pathological range.

The upper limit for normal counts quoted by Boyd in $1970(5 / \mathrm{cmm})$, Kline in $1962(6 / \mathrm{cmm})$, and Davidsohn and Henry in $1969(8 / \mathrm{cmm})$ indicates the range which has been generally accepted. These estimates are based on counting chamber methods which are known to be increasingly inaccurate as the normal range is approached. The values cited are a statement of the detection limit of the method rather than a true definition of the physiological limits of cells of the cerebrospinal fluid.

It is of interest to examine these differences in proposed normal maxima statistically. The collection of fluid by lumbar puncture by the Swinney cartridge and by the conventional test tube method may both be assumed to represent comparable random sampling events. In the case of the Neubauer counting chamber, a second random sampling of a $1 / \mathrm{cmm}$ aliquot occurs in filling the counting chamber and counting 10 squares. If one disregards all nonrandom sources of error, such as sedimented or clotted samples, or glove powder contamination being mistaken for cells, and considers only the effects of sample size and population density then the Poisson distribution should apply to the observed values for counts on a well mixed sample of cerebro- spinal fluid by the Neubauer method. Thus, in a fluid with a true average population density of $2 \overrightarrow{0}$ cells/cmm sampled in $1 \mathrm{cmm}$ aliquots observed counts will be 2 or less on only $68 \%$ of occasions. On $\overrightarrow{\vec{F}}$ the other hand $95 \%$ of samples will yield counts of $\frac{7}{0}$ 4 or fewer, so that an observed count of $>4 / \mathrm{cmm}$ 든 by the Neubauer method has only a $5 \%$ chance of $\frac{\bar{\omega}}{\omega}$ coming from a normal, ie, $2000 / \mathrm{ml}$ or less cerebro- $\mathbb{D}$ spinal fluid, and an observed count of $>5 / \mathrm{cmm}$ has a chance of only $2 \%$ of coming from such a normal population. One would therefore choose 5 or $6 / \mathrm{cmm}$. as an upper limit of normal for the Neubauer $\overrightarrow{\vec{\omega}}$ method if one wished to avoid false positive diag- $\omega$ noses in counting fluids with a true upper limit of $2000 / \mathrm{ml}$ as proposed by us. In practice non-random in errors due to failure to recognize contamination of the sample by blood and glove powder do contribute false positives, 16 such having been found in $263 \stackrel{\circ}{\circ}$ samples.

With $5 / \mathrm{cmm}$ as a limiting value false negatives $\stackrel{?}{\rightarrow}$ may be expected to be fairly common with the $T$ Neubauer method. Thus in a specimen with a true $\mathbb{D}$ population density of $5 / \mathrm{cmm}$ (which ought to be recorded as pathological) a $1 \mathrm{cmm}$ aliquot will $₹$ yield an observed count of 4 or fewer on $44 \%$ of $\vec{\varphi}$ occasions, 3 or fewer in $27 \%, 2$ or fewer in $12 \%$ This prediction is borne out by our experience indicated in figure 3. Of those with cartridge coun greater than $4000 / \mathrm{ml}$, ie, a true population densit of $>4 / \mathrm{cmm}, 23 \mathrm{had}$ Neubauer counts of 5 or more and would have been correctly assigned to the pathological category, but 11 others who had Neubauer counts of $4 / \mathrm{cmm}$ or fewer would have been wrongly classified. If one considers those who were pathological as judged by our proposed standard of $2000 / \mathrm{ml}$ on cartridge count, there were 35 patients who would have been wrongly classified on the basis of Neubauer counts of less than $5 / \mathrm{cmm}$.

Providing that the lumbar puncture needle makes an airtight fit with the cartridge so that no air is mixed with the cerebrospinal fluid during the aspiration the cytological quality of the preparations has been very good. A small quantity of air drawn through the wet filter produces severe distortion of the cells but a total cell count is still possible.

The method has been on trial for two years and is $N$ now in routine use. It has proven especially helpful N in monitoring the therapy of cases of meningeal N leukaemia where the blast cell count can be estimated reliably.

An unforeseen convenience has been the stability of stored specimens, making it possible to avoid technical call backs except in clinically urgent cases.

The material reported here forms part of a project carried out by Mrs Burechailo in partial fulfilment 
of the requirements of the Canadian Society of Laboratory Technologists for their Advanced Registered Technologists examination. Computational assistance with fig 3 was received from Dr K. L. Massey and statistical advice from Dr Donna Malcolm.

\section{References}

Boyd, W. (1970). A Textbook of Pathology, 8th ed., p. 1205. Lea and Febiger, Philadelphia, Kimpton, London.
Davidsohn, I., and Henry, J. B. (1969). Todd-Sanford Clinical Diagnosis by Laboratory Methods, 14th ed., p. 1165. Saunders, Philadelphia.

Jéquier, M., and Dufresne, J. J. (197(1)). Diagnosis of cryptococcal meningitis. (Letter), New Engl. J. Med., 286, 785-786.

Kline, T. S. (1962) Cytological examination of the cerebrospinal fluid. Cancer (Philad.), 15, 591-597.

Naib, Z. M. (1970). Exfoliative Cytopathology, 1st ed., p. 398. Little, Brown, Boston.

Wertlake, P. T., Markovits, B. A., and Stellar, S. (1972). Cytologic evaluation of cerebrospinal fluid with clinical and histologic correlation. Acta cytol. (Philad.), 16, 224-239. 